\title{
Steps forward no guarantee that health targets will be met, council says
}

$\mathrm{C}$ anada has made considerable progress in achieving the ambitious 10-year goals to strengthen health care set out by the country's federal and provincial leaders in 2004, though it is too early to predict if those goals will ultimately be met, according to the Health Council of Canada.

"If we were to use the analogy of a classroom, we are in the process of getting ready for a big exam in 2014 and, overall, the class is not ready yet," says Dr. Jack Kitts, the council's chair. "It's premature to assign a grade, but there has been a steep upswing. In the last two years, progress has accelerated and that's the reason for our cautious optimism."

In a new report, Progress Report 2011: Health Care Renewal in Canada, the health council examines the progress on promises made in 2004 by Canada's First Ministers in the 10-Year Plan to Strengthen Health Care, as well as goals set in 2003 in the First Ministers' Accord on Health Care Renewal. The report focuses on the degree of progress achieved in five areas: wait times, pharmaceutical management, electronic health records, teletriage and health innovation (www.healthcouncilcanada .ca/docs/rpts/2011/progress/2011Progress _ENG.pdf).

"The Health Council of Canada is optimistic in its assessment of progress. ... We base our optimism on work in wait times, primary health care, electronic health records, catastrophic drug coverage, reduced generic drug costs, and improvements in our capacity to collect, interpret, and use health information to improve service delivery and increase patient safety," the report states.

Though some areas have progressed more rapidly than others, all still have room for improvement. In the area of wait times, for example, Canada's First Ministers set aside $\$ 5.5$ billion to significantly reduce wait times in five priority areas: cancer, heart, diagnostic imaging, joint replacement and sight restoration.

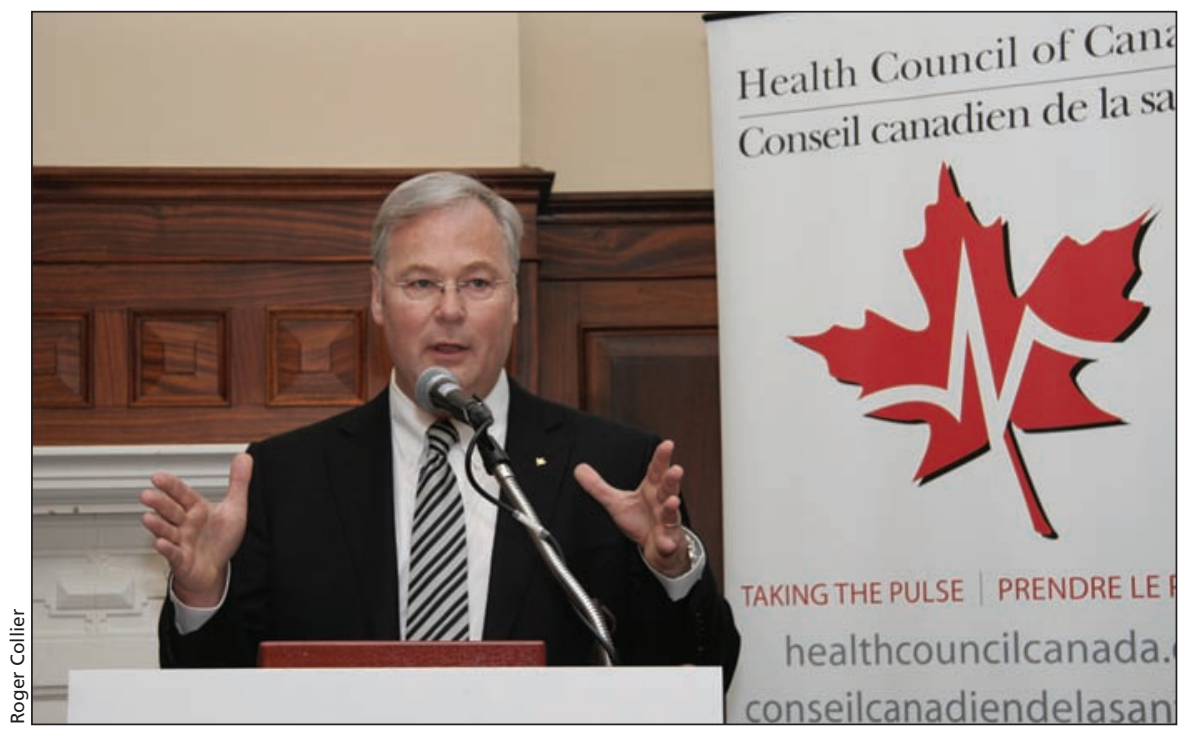

Wait time reductions could be viewed as a "success story" in Canada but challenges remain, Dr. Jack Kitts, chair of the Health Council of Canada told a press conference on May 31.

Significant reductions in wait times have occurred, making it the "success story" of the 2004 health accord, but challenges remain, Kitts told a May 31 press conference in Ottawa, Ontario. Public reporting on wait times for diagnostic imaging is poor. In Ontario, wait times for magnetic resonance imaging actually increased between 2008 and 2010. And the focus on five specific areas may have inadvertently increased wait times in other areas of health care, though provinces are beginning to address this by expanding their wait time strategies, a move Kitts applauds. "We don't want to have any poor cousins," he says.

Conversely, Canada's progress in developing electronic health records can only be viewed as a tale of frustration, the report asserts. "In a number of reports, we have called for increased use of electronic health records, and noted the low uptake of electronic medical records. The fact that most Canadian physicians still rely on paper records means patients aren't experiencing the great potential of electronic records to improve care."
In the 2004 health accord, the First Ministers vowed to accelerate the development of electronic health records. And though the federal and provincial governments have invested heavily in this area, to the tune of nearly $\$ 4$ billion, Canada's health system essentially remains a dinosaur in terms of technology. As the report notes, Canada, with only $37 \%$ of its primary care doctors using electronic medical records, ranked dead last out of 11 countries that participated in the 2009 Commonwealth Fund International Health Policy Survey.

Of course, reducing the practise of medicine to data points that can be entered into a computer is not that easy, suggests Kitts. Unlike the data captured by banks or retailers, patient information is more difficult to quantify in a consistent way. A medical diagnosis is more ambiguous than a report on monthly profits. "There is still a lot of art in the practice of medicine," says Kitts. "For an information system to work, you have to change that art into a science. It can be difficult to get consistency in the data." 
Another goal set by the First Ministers in 2004 that shows no signs of materializing is the creation of a national strategy for pharmaceuticals. "In our 2009 publication, A Status Report on the National Pharmaceuticals Strategy: A Prescription Unfilled, we reported that the strategy has stalled," states the council's report. "Two years later, it has not gained momentum." Nor has the practice of e-prescribing, also mentioned in the 2004 health accord, become widespread in Canada.

Though there has been some progress in several areas of pharmaceutical management — providing catastrophic drug coverage, increasing pharmacists' scope of practice, reducing generic drug prices and implementing drug information systems - the progress varies substantially across the country.

The federal government has a role to play in ensuring Canadians in all provinces and territories have equitable access to the drugs they need, suggests Kitts. "What we would like to see from the federal level is an umbrella role to make sure the gaps between jurisdictions aren't widening."

In the other two areas examined in the report — teletriage and health innovation - the council offered praise, though of the lukewarm variety for the latter. Teletriage has become widespread across the country, providing Canadians with telephone access to professionals who can assess their symptoms. Though Canada is not a world leader in health innovation, it has nevertheless met the commitments made by the First Ministers, the report states, though patients don't appear to be seeing the fruits of that innovation at the bedside.

The report concludes by suggesting that federal and provincial governments now turn their attention toward health human resource planning, home care and accountability mechanisms such as improved reporting requirements. Roger Collier, CMAJ

CMAJ 2011. DOI:10.1503/cmaj.109-3912 